CORRECTION

https://doi.org/10.1038/s41586-018-0427-1

\title{
Author Correction: Cryo-EM \\ structure of a fungal mitochondrial calcium uniporter
}

Nam X. Nguyen, Jean-Paul Armache, Changkeun Lee, Yi Yang, Weizhong Zeng, Vamsi K. Mootha, Yifan Cheng, Xiao-chen Bai \& Youxing Jiang

Correction to: Nature https://doi.org/10.1038/s41586-018-0333-6, published online 11 July 2018.

In this Article, reference 15 should be "Lee, S. K. et al. Structural insights into mitochondrial calcium uniporter regulation by divalent cations. Cell Chem. Biol. 23, 1157-1169 (2016)." instead of "Kishnani, P. S. et al. Immune response to enzyme replacement therapies in lysosomal storage diseases and the role of immune tolerance induction. Mol. Genet. Metab. 117, 66-83 (2016).". In addition, references 32-50 in the Methods should be renumbered so that reference 32 should be reference 50 and references 33-50 should be references 32-49, respectively. These errors have been corrected online. 